\title{
Quality Standards for Student Cultivation in Higher Vocational Institutions: Interpretation and Optimization
}

\author{
Jianhua Shu ${ }^{1, a^{*}}$, Jianghua $\mathrm{Fu}^{1, \mathrm{~b}}$ and Xiangfeng Meng ${ }^{1, \mathrm{c}}$ \\ ${ }^{1}$ Suzhou Polytechnic Institute of Agriculture, Suzhou, Jiangsu, China, 215008 \\ asjhszny@126.com, bfujianghua@sina.com, ${ }^{c} 372820571 @ q q . c o m$
}

Keywords: Higher vocational institution; Student cultivation; Quality standards

\begin{abstract}
Based on conceptual interpretation, this paper clarifies the quality standards for cultivating students in higher vocational institutions in terms of standards of student quality, standards of educational and teaching work, standards of educational and teaching management, and standards of educational and teaching evaluation. In addition, five principles for optimizing the quality standard system of student cultivation in higher vocational institutions are formulated, namely, the principle of education by virtue, the principle of career orientation, the principle of systematic design, the principle of consensus, and the principle of continuous improvement.
\end{abstract}

\section{Introduction}

In June 2015, the Ministry of Education issued the Circular for the Establishment of Diagnosis and Improvement System for Teaching Work in Vocational Institutions, which stipulates that vocational institutions establish a normalized mechanism to self-guarantee their educational quality, establish a diagnosis and improvement system for teaching work, and conduct teaching diagnosis and improvement in an all-round way[1]. Quality standards are the core content of the internal quality assurance system in higher vocational institutions and the important basis for teaching work diagnosis and improvement. The development of educational quality standards is the groundwork for perfecting the internal quality assurance system. As vocational education directly caters for the workplace and closely connects with industries and enterprises, it is both necessary and feasible to strengthen the educational quality standards. Compared with countries such as Germany and Australia, where vocational education is highly advanced, China is considerably lagging behind in its quality standards for vocational education. For this reason, the author put forward a proposal in On the Policy-Making of Establishing Standards for Programs of Vocational Education [2], in an effort to call for speeding up this undertaking. At present, common problems in quality standards in higher vocational institutions include: standards being ungrounded, standards being unsystematic, standards being one-sided, standards being unspecific, standards being featureless, and standards being loosely implemented. To tackle these problems, it is urgent to clarify related conceptual notions, uphold the optimizing principles and formulate ideas for strengthening quality standards.

\section{Notions and Connotations of Quality Standards for Higher Vocational Institutions}

To accurately interpret the connotation of the quality standards for student cultivation, it is a prerequisite to clearly define such notions as quality, standard, and educational quality standards.

Related Notions. Quality: Quality is vital to an organization. According to the world renowned quality control guru Joseph M. Juran, in his classic Quality Control Handbook, all human communities (industrial companies, schools, hospitals, churches, governments) are all engaged in providing products or service to human communities. Only when these products or service satisfy all the needs of customers in terms of price, time of delivery, and fitness for use, can this relationship be constructive. Of all the needs, the degree to which the product successfully fits the purpose of the customer is called fitness for use. The concept fitness for use or purpose is conventionally expressed by the word quality, which is a common notion applying to all products and service[3]. This is the source from which the definition of 
quality by the International Organization for Standardization (ISO) originated. In the case of education, students are not products but educational targets and meanwhile "customers" of educational service. Educational quality is measured not by sheer technical standards, but commonly by fitness for use or degree of fitness, such as the degree of satisfaction rated by employers.

Standards: The definition given by the International Organization for Standardization (ISO) and the International Electrotechnical Commission (IEC) is: "A standard is a document, established by consensus and approved by a recognized body, that provides, for common and repeated use, rules, guidelines or characteristics for activities or their results, aimed at the achievement of the optimum degree of order in a given context." "Standards should be based on the comprehensive achievements of science and practice for the purpose of increasing optimal social benefits [4]." The Standardization Administration of China adopts the same definition for quality as well. In the final analysis, standards are requirements, which are requirements of the markets and customers.

Worldwide, standards can be categorized into international standards, regional standards, national standards, industry standards, local standards and enterprise standards. The ISO 9000 family of quality management systems standards belongs to international standards, which specifies its application to educational services.

At present, there are four levels of standards: national standards, industry standards, local standards and enterprise standards, which are classified by their scopes of application. The principle is that the lower-level standards have stricter requirements than the upper standards do. In the light of this principle, the national standards have the lowest requirements, while the enterprise standards stipulate the highest requirements. The legal force of standards varies depending on whether they are obligatory or recommendatory, the former with code starting with the letters GB, which are mandatory standards enforced by law and administrative regulations, the latter with code starting with GB/T, which are recommended to voluntarily adopt via economic means or market regulation. According to their nature, there are technology standards, work standards and management standards. Technology standards are for technological matters in standardization that require coordination and specification. Work standards are for work matters in standardization that require coordination and unification, setting out quantitative or qualitative requirements, and activity procedures and assessment requirements, for people and organizations with their duties and authority in their specified posts of production, business and management. Management standards are for managerial matters in standardization that require coordination and specification.

Educational Quality Standards. Educational quality standards are educational specifications formulated to achieve a planned educational goal within a certain period [5]. The National Outline for Medium- and Long-Term Educational Reform and Development (2010-2020) requires "formulating national standards for educational quality, and establishing and improving an educational quality assurance system," with part of the national standards including quality standards for higher education issued. The national standards for higher educational quality are the basic standards of educational quality for all levels, types, forms, and disciplines of institutions at the stage of higher education on the national macro-level, which are also the minimum requirements of educational quality for all institutions of higher learning [6]. Existing national standards for higher education include Standards for the Setup of Higher Vocational Institutions (Provisional) (issued on March 15, 2000), Professional Ethics Code for Teachers in Institutions of Higher Learning (issued on December 30, 2011), Standards for Ideological and Political Theory Curriculum Construction in Institutions of Higher Learning (issued on September 10, 2015). Unlike standards for other industries, which are labeled with numbers and specified whether they are mandatory or recommendatory, these education-related standards are all issued by the nation's educational administrative departments and are required to be implemented by higher educational institutions, with a nature of mandatory national standards.

In the area of higher vocational education, the Ministry of Education makes clear requests about improving the quality standards system in its document Suggestions on Deepening Teaching Reform of Vocational Education to Improve the Quality of Student Cultivation, stating that the MOE 
will, in the light of the actual situation of social and economic development, regularly revise and release program catalogues, set out curriculum standards for compulsory fundamental courses and certain elective courses, teaching standards for programs, internship standards, and specifications for teaching facilities and equipment. Provincial educational administrative departments are required, on the basis of relevant national standards, to administrate the development of teaching guidelines for programs and standards for curricula with regional characteristics, and develop those standards that are in line with advanced standards of the world. Based on their educational orientation, service targets and innovation and entrepreneurship education goals, vocational institutions are encouraged to bring in and make use of job specifications of companies in making student cultivation plans [7]. In November 2012, the Department of Vocational and Adult Education under the MOE officially published separate standards for 410 respective programs of higher vocational education covering 18 subject categories. In July, 2017, the general office of MOE released separate Standards for Program Internship of Vocational Institutions covering a first batch of 70 programs under 30 subject categories. Such standards belong to work standards by nature, and function more like recommendatory standards judging by their legal binding.

\section{Connotation of Quality Standards for Student Cultivation}

Existing literature suggests that more researches have been done on quality standards for higher education than on quality standards for student cultivation in higher educational institutions, with the latter being less authoritative. Dongming Huang holds that quality standards for student cultivation in higher educational institutions are a conglomeration of all categories of set standards and measurable benchmarks in the whole process of student cultivation for the purpose of improving the quality of student cultivation so as to meet the demand of social, economic, scientific, technological and cultural development[8]. The author agrees with the above assertion in that it interprets the connotation of the quality standards for student cultivation in a comprehensive and accurate way. Firstly, it specifies the objectives of setting quality standards for student cultivation, i.e. the internal need to improve the quality of student cultivation and the external need to meet the demand of social, economic, scientific, technological and cultural development; secondly, it uses a system concept by targeting the whole process of student cultivation; and finally, it indicates the content of the quality standards for student cultivation, which are are a conglomeration of all categories of set standards and measurable benchmarks.

In terms of the connotation of quality standards for student cultivation, there are differences in standards specifications, standards setting subjects, approaches and processes of implementation between higher vocational institutions and general higher educational institutions because of their respective nature, goals, functions and tasks [9]. Literature research shows there have been controversies and even logical confusions about the definition and connotation of quality standards for student cultivation. Some people interpret quality standards for student cultivation as objectives and specifications of student cultivation. Others identify the quality standards with quality evaluation standards such as employment rate, employment quality, and customer satisfaction. From the perspective of notion and nature of quality standards, the author argues that the quality standards for student cultivation must comprise four components, namely, quality standards for students, work standards for education and teaching, and evaluation standards for education and teaching, which form a standards system. Quality standards for students are specific requirements of objectives and specifications for student cultivation, including moral character standards, overall aptitude standards, academic performance standards, professional skill standards, overall professional competence standards, and innovative and entrepreneurial ability standards. Work standards for education and teaching are set for matters that require coordination and unification in the work of education and teaching, which consist of program construction standards, curricula standards, work protocol for teachers, and internship standards. Managerial standards for education and teaching are for managerial matters that require coordination and unification in educational and teaching management, which include management procedures for student cultivation plans, management procedures for program 
configuration and regulation, management procedures for internship. Evaluation standards for education and teaching are set for evaluating matters such as educational and teaching agents, conditions, activities, management, and performance, which may include evaluation standards for student source, evaluation standards for programs, evaluation standards for curricula, evaluation standards for teaching quality of teachers, and evaluation standards for performance and achievements of students.

\section{Principles of Optimizing the Quality Standards for Student Cultivation}

The Guidelines for Internal Quality Diagnosis and Improvement System in Higher Vocational Institutions (Provisional) indicates: "towards the goal of improving quality standards and mechanisms to raise the degree of satisfaction of interested parties with student cultivation, by following the working policy of needs orientation, self assurance, pluralistic diagnosis, and focusing on improvement, higher vocational institutions are guided to perform their duties as agents of student cultivation and construct a normalized internal quality assurance system and sustained operational mechanism of diagnosis and improvement to constantly enhance the quality of student cultivation [10]. In line with these guidelines, higher vocational institutions must optimize the internal quality assurance system to diagnose and improve teaching work. There are five principles for strengthening the construction of quality standards system for student cultivation: the principle of cultivation by virtue is about the foundation; the principle of career orientation is about the content; the principle of consensus is about the approach; the principle of systematic design is about the methodology; and the principle of continuous improvement is about the procedure.

The Principle of Cultivation by Virtue. Cultivation by virtue is the fundamental task of education, with no exception for higher education. At the National Conference on Ideological and Political Work of Higher Educational Institutions held in December 2016, CPC General Secretory Xi Jinping reiterated that higher educational institutions should maintain cultivation by virtue as the pivot of their work and integrate ideological and political work into the whole process of education and teaching to realize the all-round development of students. When setting out quality standards for student cultivation, higher vocational institutions should base on cultivation by virtue as the general requirement and basis, follow the "3-link chain" of goal-standards-evaluation, and incorporate the objectives of student cultivation into standards, rules, and specifications, which can then be converted into a parameter system of assessment. In such a way of analyzing and linking all the variables, the validity and reliability of the quality standards for student cultivation could be increased.

The Principle of Career Orientation. Higher vocational education belongs to the type of higher education that provides for the needs of highly qualified technical and skilled personnel in sectors of production, construction, business and service. It is imperative to stick to its aim of serving development, keep its orientation of promoting employment, and follow the principle of career orientation. Emphasis should be laid on cultivating students in craftsmanship, professional quality, comprehensive career competence, and innovative and entrepreneurial abilities, so as to prepare students for future careers to realize their dreams while raising employment rate and employment quality. It is highly necessary for higher educational institutions to uphold the principle of career orientation to manifest the characteristics of their quality standards for student cultivation.

The Principle of Consensus. The essential characteristics of higher vocational education is the integration of production with teaching and combination of work with study. The only way to the cultivation of students for higher vocational education is school-enterprise cooperation and joint cultivation. In this sense, higher vocational education is characterized of cross-border education, which involves multiple agents with closer ties and greater interest relevance between each other. Therefore, in the process of setting quality standards for student cultivation, higher vocational institutions should follow the principle of joint-construction involving the government, industries, schools and enterprises by consulting government agencies, industries, enterprises, teachers, students and parents and soliciting opinions and suggestions from the media and the public. On the basis of equality and consensus, the joint operation by the government, society and the institution will enhance the adaptability of the quality standards for student cultivation. 
The Principle of Systematic Design. The quality standards for student cultivation in higher vocational institutions are a comprehensive system of standards covering the whole process of student cultivation, including quality standards for students, work standards for education and teaching, managerial standards for education and teaching, and evaluation standards for education and teaching. The design of the standards should be carried out on the basis of existing requirements of the state and local educational administrative departments and relevant standards in force. Consideration should be given to the schools' own conditions, traditions and characteristics, while the interest concerns of all parties should be balanced. Only by means of policy study, theoretical guidance, investigative research, top-down design, and system optimization, can the systematicity of the quality standards for student cultivation be enhanced.

The Principle of Continuous Improvement. "Continuous improvement" is one of the 8 quality principles in the ISO 9000 family of quality management systems standards, which refers to the ongoing efforts of reform and improvement made by organizations to improve products, services or processes in their fitness, competitiveness, and performance. These efforts can seek "incremental" improvement over time or "breakthrough" improvement all at once. With the advancement of science and technology, the deepening of educational reform, the improvement of educational conditions, the enhancement of educational standards, and the changing and raised quality requirements for internal and external agents of higher vocational education, it is imperative for quality standards of student cultivation to be continuously improved as well, which requires higher vocational institutions to establish a system of continuous improvement of quality standards, by means of regular revision and perfection in the form of "3-step cycle" of formulation, implementation, and diagnostic prescription. As a result, the quality standards for student cultivation can be continuously updated.

\section{Acknowledgement}

This paper is attributed to the support of Jiangsu Provincial Commission of Agriculture for sponsoring the research project Federation-based Quality Assurance System in Higher Vocational Institutions of Agriculture: Research and Practice (No. JSNZJ201607; Lead: Shu Jianhua), under the category of Research Projects on Educational and Teaching Reform and Development of Vocational Education of Agriculture in Jiangsu Province 2016. It is also the interim achievement of Research on the Mechanism of Federation-based Teaching Material Construction for Vocational Education of Agriculture (No. 2016-135-Y-110; Lead: Shu Jianhua), under the project category of Projects of the National Thirteenth Five-year Plan for Vocational Education of Agriculture.

\section{References}

[1] General Office of the Ministry of Education, the Circular for the Establishment of Diagnosis and Improvement System for Teaching Work in Vocational Institutions (2015\#2), 2015. (In Chinese)

[2] J.H. Shu, Policy Suggestions on Formulating Program Standards for Vocational Education, Vocational Education Forum, 2005, No. 10, pp.6-9. (In Chinese)

[3] M.X. Sun, H.P. Liu, A Guide to the Establishment and Implementation of Educational Quality Management Systems in Institutions of Higher Learning, Petroleum Industry Press, Beijing, 2003.(In Chinese).

[4] Y.H. He, A Tentative Analysis on the Composition and Structure of Teacher Education Standards, Teacher Education Research, 2007, No. 1,p.37. (In Chinese)

[5] Research Team of Educational Quality Standards of Educational Science Institute of China, National Education Quality Standards and Formulation, Education Research,2013,No.6, pp. 4-16. (In Chinese)

[6] J. Lin, The System and Construction of the National Quality Standards for Higher Education, Higher Education of China, 2016, No. 6, pp. 8-11. (In Chinese)

[7] Ministry of Education, Suggestions on Deepening Teaching Reform of Vocational Education to Improve the Quality of Student Cultivation (2015\#6), 2015. (In Chinese) 
[8] M.D. Huang, Thoughts on the Construction of Quality Standards for Student Cultivation in Chinese Universities, Chinese University Teaching, 2017, No.3, pp.38-42. (In Chinese)

[9] H.Y. Xiao, A Tentative Discussion on the Classification of Higher Education and Boundaries of Quality Standards, Higher Education Research, 2005, No.8, pp.38-41.(In Chinese).

[10] Department of Vocational and Adult Education of Ministry of Education, Circular on the Issuing of the Tentative Guidelines for Diagnosis and Improvement of Internal Quality Assurance System in Higher Vocational Institutions, Correspondence of Vocational and Adult Education, 2015, No.169. (In Chinese) 